\title{
Analysis of Technical Efficiency of Wheat Production in Horo District of Horoguduru Wollega Zone, Oromia region, Ethiopia
}

\author{
Hika Wana*1 Lemmessa Dhugasa ${ }^{2}$ \\ 1.Wollega university, department of agricultural economics, shambu campus, P.O.Box 38 \\ 2.Commercial bank of Ethiopia, assistant manager at shambu, Horo branch, P.O.Box 38
}

\begin{abstract}
The aim of the study was to measure the levels of technical efficiency of wheat producers and identify factors affecting them in Horo district of Horoguduru Wollega Zone, Oromia Region, Ethiopia. The study was based on cross-sectional data collected in 2016/17 production season from 124 randomly selected farm households. Stochastic production frontier model was used to estimate technical efficiency levels and used to identify factors affecting efficiency levels. Accordingly, the mean technical efficiency of sample household's was $63.9 \%$.The results indicated that there was substantial amount of in efficiency in wheat production in the study area. Land, seed, DAP and chemical were the variables that positively affected the production of wheat. Results of the factor model revealed that family size, experience in wheat production and extension contact positively and significantly affected technical efficiency. Total cultivated land had a significant negative effect on technical efficiency. Results indicate that there is a room to increase the efficiency in wheat production of the study area. Therefore, government authorities and other concerned bodies should take into consideration the above mentioned socio economic and institutional factors to improve the productivity of wheat in the study area.
\end{abstract}

Keywords: Horo district, technical efficiency, wheat, stochastic

DOI: $10.7176 / \mathrm{JNSR} / 9-13-03$

Publication date:July $31^{\text {st }} 2019$

\section{INTRODUCTION}

\subsection{Background of the Study}

Agricultural sector is a cornerstone of many developing countries including Ethiopia, in promoting economic growth and development of the economy. It accounts $46 \%$ of GDP, over $90 \%$ of the foreign exchange earnings, $83 \%$ of employment generation and providing $70 \%$ raw material for the industries in the country (EPOSPEA, 2015). The livelihood of about $90 \%$ of the poor is fully or partly dependent on this sector (Yu et al., 2011). Besides, $95 \%$ outputs obtained from the sector was mostly depends on rain-fed production system that dominated by smallholders (MoARD, 2011). Thus, it is not surprising that policy action in Ethiopia is largely based on influencing the dynamism of the agricultural sector.

Agriculture has always been an important sector in Ethiopia. About $85 \%$ of the population is directly or indirectly engaged in agriculture. This occupational status placed the smallholder farmers as a central focus of development policies and strategies. The sector is also the main source of foreign currency for it accounts for about $45 \%$ of the total export of the country. The export diversification prospect is mainly focused on agricultural products and this would also bolster the contribution of agriculture for the export sector. Moreover, agriculture contributes about $50 \%$ of the gross domestic product of the country. Befkadu and Berhanu (2000) indicated that the performance of the Ethiopian macro economy is highly correlated with the performance of the agricultural sector. In the years that nature generously provided the rains in the appropriate times, we also see a reasonably good overall macroeconomic performance.

All these facts direct development policies, strategies and objectives towards improving the agricultural sector and the rural population. In view of this various efforts were made by the preceding regimes. However, the sector could not produce enough food to support the rapidly increasing population. Amare (1998) by fitting exponential growth function to the production of major crops for the year 1979/80-1993/94 found that the average growth rate was $0.3 \%$ per annum. Nevertheless, the population is reported to be increasing at about $3 \%$ per annum

(Amare, 1998). Consequently, food aid is increasing at 16.2\% perannum. Therefore; the country's dependence on external food aid is growing at an alarming and rapid rate. The study zone that has been one of the sources of grain crops for other areas is now becoming dependent on external aid.

In fact, CSA (2015 and 2016) reported that there was an increase in the total production. However, increment in production of wheat from 39,251,741.35 quintal in 2013/14 to42, 315,887.35 in 2014/15 was not attributed to productivity improvement alone. There was also an increase in area of cultivated land in the same years. However this reported increase in production was brought at the cost of environmental degradation. Those lands that should have been left idle, for environmental maintenance are recently brought into cultivation. Due to this main reason, soil degradation is highly aggravating than ever before.

Hence, increasing the cultivated land at the cost of land degradation is not sound not only due to environmental degradation but also it is not also a sustainable way of solving food insecurity. The growth rate was 
estimated by fitting data obtained from (CSA, 2015/16) to growth function model. Thus possible ways should be sought to alleviate food shortage and food insecurity. One way of mitigating the problem is increasing the use of improved technologies and improving the efficiency of farmers in using inputs. However, how much farmers are efficient in the region in not known. Thus, there is no evidence in the study area as to the level of technical efficiency. This paper is condacted to measure the gap between the actual and the potential output of wheat and also identifies the main determinants of this gap.

\section{Statement of the Problem}

Since the start of extension services some 60 years ago, a lot of efforts have been made to increase productivity of grain. Though, a lot of efforts were made to introduce different technologies to improve the productivity, the country could not yet feed the population in a sustainable way. Agricultural production in Ethiopia was not stable and this is evidenced by the simple fact that there were recurrent food shortages in the country. Various efforts have been made to insure food self-sufficiency in the country. Nevertheless, in the context of food self-sufficiency, the rural population that ought to have at least fed the remaining $15 \%$ of the urban population could not even sustain itself. In addition to the recent food security programs, a lot of efforts are being made to improve the agricultural sector. Various efforts were made in the past to improve the productivity level of wheat and cereal crops mainly through the introduction and dissemination of agricultural technologies especially fertilizers and improved seeds. This can be evidenced by rapid increase of the use of these inputs in the study zone.

If the existing production system is not efficient, introduction of new technology could not bring the expected improvements in the productivity of wheat and other crops. Given the existing technology, improvements in the level of technical efficiency will enable farmers to produce the maximum possible output from a given level of inputs. Hence improvement in the level of technical efficiency will increase productivity. Theoretically, introducing modern technologies can increase agricultural output. However, according to Tarkamani and Hardarkar, (1996, cited in Getu, 1997) in areas where there is inefficiency, trying to increase a new technology may not have the expected impact and "there is a danger of trying to rediscover the wheel" if the existing knowledge is not efficient.

Agricultural output can be increased either through introduction of modern technologies or by improving the efficiency of inputs such as labour and management at the existing technology. In other word, productivity can be increased through dissemination of improved technologies such as fertilizer and high yielding varieties (HYV) and/or by improving the productive capacity of say the manager (the farmer). These two are not exclusive because the introduction of modern technology could not bring the expected shift of production frontier, if the existing level of efficiency is low. This implies the need for the integration of modern technologies with improved level of efficiency. But what is the existing level of efficiency of farmers? Is there any room for improvement inthe level of efficiency? What are the main causes for the existing level of inefficiency (if any)? What are the main possible solutions to improve the existing level of inefficiency? By what level of input (say labour or fertilizer) be reduced to obtain the existing level of output or in other words, by what level can output be increased given the existing level of inputs? This study attempts to answer the above questions.

Despite of the fact that Horo district has high potential for wheat production, the yield has been 13 quintals per hectare which is below regional average in $2016 / 17$ production season. Its production only increased by .05\% and $0.02 \%$ in 2016 and 2017, respectively (HDARDO, 2017). This shows as production and productivity of the crop remain in a question for a long period of time in Ethiopia in general and in study area, Horo in particular. Low production and productivity are the characteristics of several wheat farmers in the country, which needs the specific focus of researchers to measure technical efficiency of wheat and identify factors influencing productivity of wheat. Therefore this study focuses on estimating level of efficiency and identifies factors that distort productivity of wheat in the study area. Furthermore, there is no standardized empirical research which has been conducted on technical efficiency of wheat in this specific area so far. Cognizant of these facts, this study was undertaken to narrow the wide research gap that has been observed currently on technical efficiency of wheat in the study area.

\section{Objectives of the Study}

The overall objective of the study will tries to assess technical efficiency of small holder farmers in the production of wheat in Horo district of Horo guduru Wollega Zone

\section{Specific objectives of the study}

To measure the level of technical efficiency of wheat

To identify the sources of differences in technical efficiency 


\section{RESEARCH METHODOLOGY}

Description of the Study Area

Horro Districtis one of the Districts found in HorroGuduruWellega Zone and located at center part of zone. Today this district is sub-divided in to 11 farmer associations for its administrative purpose. Shambuis the capital town of the district located at the center of the zone and $314 \mathrm{~km}$ from capital town of Oromia called Finfinne.Shambu as an administrative center was established in 1911 Ethiopian calendar.Horro is one of the districts found in Horro GuduruWellega. It is bounded from the east AbbayComman District, north Jardagajarte District and amhara region, west Abe Dongoro and GudayaBila District and South JimmaGanati\&Jimma Rare District.

According to 2007 Population and Housing Census result, the total population of the district was estimated to be90,665 in 2005EC. The rural population was 85,758 (of which male 42,650 and female 43,107 while the urban population was4,907 (of which male 2,450and2,457females).

The attitude range of the district is $2500 \& 1350$ above and below sea level respectively. The mean annual rain fall of the woreda is about $2250 \mathrm{~mm}$ and the mean daily temperature is oscillates between $15-27$ degree Celsius.Livestock production is the e branch of agricultural activity and part of economic base of the country. Ethiopia in general and Oromiya in particular is known for its animal rearing especially for use of labor: Ox, horse, donkey and camel and for meat, milk and milk products. The most common domestic animals in Horodistrict are cattle, goats, sheep horses, mules, donkeys and poultry.

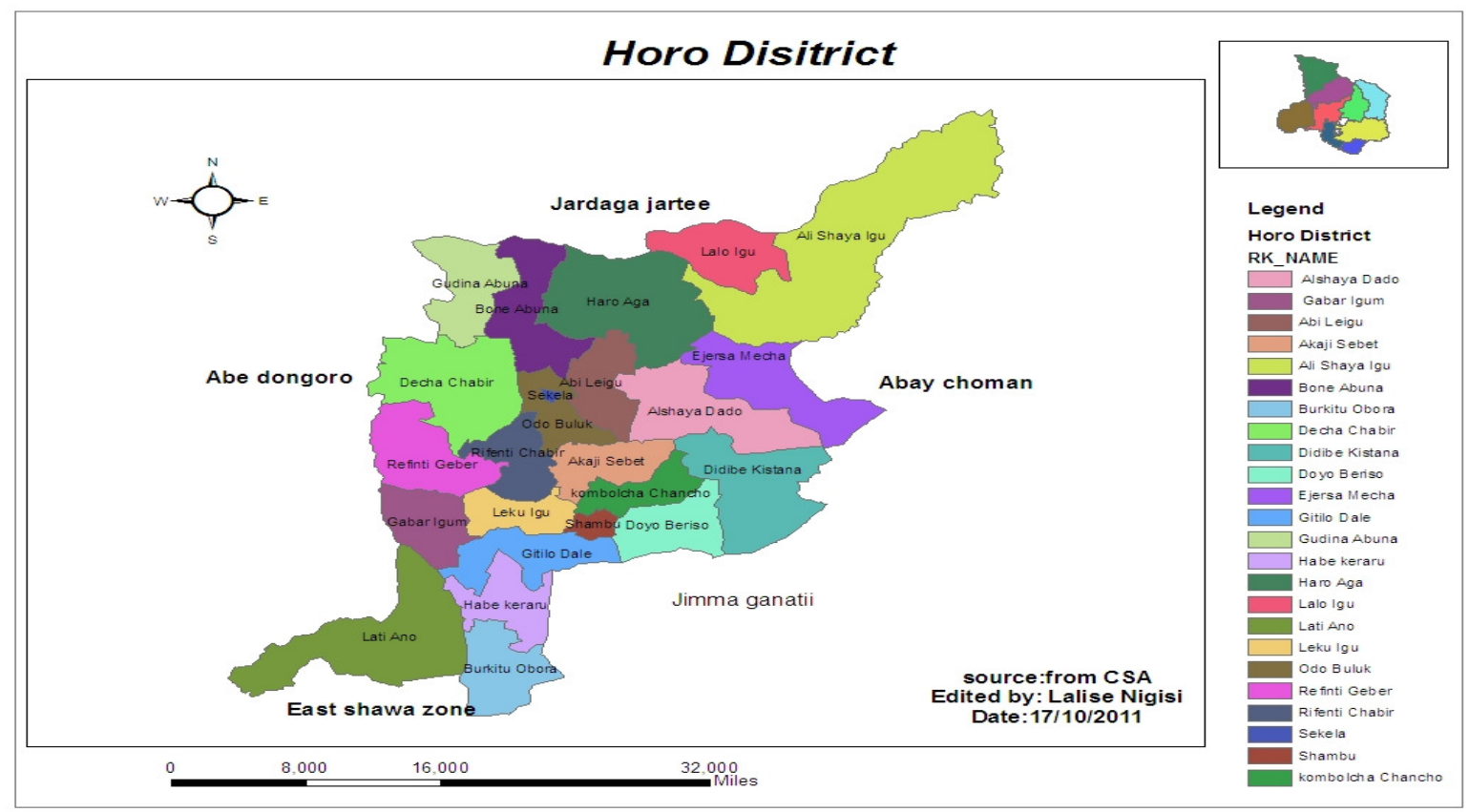

Figure 1: Map of the study area

\section{Types, Sources and Methods of Data Collection}

For this study quantitative data were collected mainly. It include The Factors affecting efficiency

Age of a household head ,Education of the household head ,Family size, Experience in wheat production, Distance of wheat plot from homestead, Livestock holding, Total cultivated land, and The Soil fertility status. Data source for this study was both primary and secondary data. Primary data was collected using formal survey.

Primary data: primary source was smallholder farmers randomly selected from rural kebeles in the district before the beginning of data gathering using interview schedule, training was given to enumerators. Before data collection, the questionnaire was pre-tested on five farmers to evaluate the appropriateness of the design, clarity and interpretation of the questions, relevance of the questions and time taken for an interview. Hence, appropriate modifications and corrections were made on the questionnaire. These enumerators collected the required data from the producer farmers using a pre-tested interview. Hence, appropriate modifications and corrections were made on the questionnaire. These enumerators collected the required data from the producer farmers using a pre-tested interview schedule. To collect primary data, a semi structured questionnaire was prepared and used.

Secondary data: it was collected by reviewing documents of secondary sources namely, both zonal and district's office of agriculture and rural development; offices published and unpublished thesis documents, books of Central Statistical Authority (CSA), and books of Ministry of Agriculture. 


\section{Sample Size and Sampling Technique \\ Producers sampling}

Horo district was purposively selected for the study because of the presence of large number of wheat producing farmers and its extent of production. In order to select representative sample technical efficiency in wheat production, this study implemented two stage sampling procedure.

In the first stage, out of 11 wheat producing kebeles in Horo district, a total of 3, namely kombolcha-chancho, Gitilo-dale and Akaji-sabat were selected randomly.

In the second stage, using the list of the farmers from the sampled kebeles, 124 sampled respondents were selected randomly based on proportional to the population size of the selected kebeles.

\section{Sample size determination for producers}

The sample keeping the proportion to each kebeles were selected by using Yamane (1967) sample size formula.

$$
\mathrm{n}=\frac{\mathrm{N}}{1+\mathrm{N}\left(\mathrm{e}^{2}\right)}
$$

Where, $\mathrm{n}$ is sample size, $\mathrm{N}$ is number of Household and e is the desired level of precision. By taking e as $9 \%$, and the total household of 5703 the sample size was 124

$\mathrm{n}=\frac{5703}{1+5703\left(.09^{2}\right)}=124$

\section{Method of Data Analysis}

Two types of analysis, namely descriptive and econometric methods were used to meet the objective of the study.

\section{Descriptive Analysis}

This method of data analysis refers to the use of ratios, percentages, means, and standard deviations in the process of assessing the Wheat production and its productivity and also factors affecting efficiency in the study area.

\section{Econometric model}

Wheat production in particular and crop production in general in the study area are likely to be affected by random shocks such as weather, pest infestation and drought. In addition, measurement errors are likely to be high. The difference in output as a result of these random shocks and measurement errors are not due to operator's inefficiency or misallocation of resources. In such a condition where random shocks and measurement errors are high a model that accounts for the effect of noise is more appropriate to choose. Thus a stochastic frontier model was selected in the analysis of technical efficiency of wheat production in Horo district. This was due to the fact that one of the appealing features of SPF is that it accounts for random shocks and measurement errors. Therefore the general stochastic frontier model developed independently by Aigneret al. (1977) and Meeusen and ven den Broeck (1977) in which an additional random error, vadded to the non-negative random variable, $\mathrm{u}_{\mathrm{i}}$.Taking natural logarithms, the model becomes:

$\ln y_{i}=\beta_{\circ}+\ln x_{i} \beta-u_{i}$

Where: $\operatorname{lnq}_{i}$ is the natural logarithm of the output of the $i^{\text {th }}$ firm;

$\ln \mathrm{x}_{\mathrm{i}}$ is the natural logarithms of inputs;

$\beta$ is a column vector of the unknown parameters to be estimated;

$\mathrm{u}_{\mathrm{i}}$ is a non-negative random variable associated with technical inefficiency, representing the shortfall of actual output from its maximum possible value. For this study Cobb-Douglas production function was used. In similar studies the model is widely used (Ananeaniet al.2011). In the second stage Technical efficiency score regressed on explanatory variable(factors affecting efficiency) and it is specified in abstract term as specified below

$$
T E=\ln A+\alpha_{1} \ln x_{1}+\alpha_{2} \ln x_{2}+, \ldots \ldots \alpha_{n} \ln x_{n}+\beta_{1} D_{1}+\beta_{2} D_{2}+, \ldots \ldots, \beta_{n} D_{n}+u_{i}
$$

Where:

$\mathrm{TE}=$ Technical efficiency score of household

$\mathrm{A}=$ the intercept that reveals combined impact of production

$\mathrm{X}_{1}, \mathrm{X}_{2}, \ldots . . \mathrm{X}_{\mathrm{n}}$ : are continuous explanatory variables

$\mathrm{D}_{1}, \mathrm{D}_{2}, \ldots \ldots, \mathrm{D}_{\mathrm{n}}$ : dummy variables

$\alpha_{1}, \alpha_{2}, \ldots \ldots \alpha_{n}:$ are coefficient/parameters of explanatory variables

$\beta_{1}, \beta_{2}, \ldots . \beta_{n}$ : are coefficient /parameters of dummy variables

Parameters: $\alpha_{1}, \alpha_{2}, \ldots \ldots \alpha_{n}$ and $\beta_{1}, \beta_{2}, \ldots . \beta_{n}$ was estimated by MLHM (Maximum likelihood method) methodology. This stochastic production function was estimated by using maximum likelihood method. As far as the functional form is concerned, cobb-Douglas and Trans log are most appropriate. Therefore cobb-Douglas 
functional form was used in empirical estimation of frontier model. According to Aigneret al.(1977), the symmetric component $\left(\mathrm{v}_{\mathrm{i}}\right)$ is assumed to be independently and identically distributed as $\mathrm{N}\left(0, \sigma_{\mathrm{v}}^{2}\right)$. On the other hand, $\mathrm{u}_{\mathrm{i}}$ is non-negative truncated half normal random variable with zero mean and constant variance, $\sigma_{\mathrm{u}}^{2}$.

Aigneret al.(1977) proposed the log likelihood function for the model in equation (3.2) assuming half normal distribution for the technical inefficiency effects $\left(\mathrm{u}_{\mathrm{i}}\right)$. They expressed the likelihood function using $\lambda$ parameterization, where $\lambda$ is the ratio of the standard errors of the non-symmetric to symmetric error term (i.e. $\lambda=$ $\left.\sigma_{\mathrm{u}} / \sigma_{\mathrm{v}}\right)$. However, Battese and Corra (1977) proposed that the $\gamma$ parameterization, where $\gamma=\sigma_{\mathrm{u}}^{2} /\left(\sigma_{\mathrm{v}}^{2}+\sigma_{\mathrm{u}}^{2}\right)$, to be used instead of $\lambda$. The reason is that $\lambda$ could be any non-negative value while $\gamma$ ranges from zero to one and better measures the distance between the frontier output and the observed level of output resulting from technical inefficiency.

However, there is an association between $\gamma$ and $\lambda$. According to Bravo and Pinheiro (1997) gamma ( $\gamma$ ) can be formulated as:

$\gamma=\lambda^{2} /\left(1+\lambda^{2}\right)$

Hence, by following Battese and Corra (1977) the log likelihood function of the model is specified as:

$\ln (\mathrm{L})=-\frac{\mathrm{N}}{2}\left(\ln \left(\frac{\pi}{2}\right)+\ln \sigma^{2}\right)+\sum_{\mathrm{i}=1}^{\mathrm{N}} \ln \left[1-\Phi\left(\frac{\varepsilon_{\mathrm{i}} \sqrt{\gamma}}{\sigma^{2}} \sqrt{\frac{\gamma}{1-\gamma}}\right)\right]-\frac{1}{2 \sigma^{2}} \sum_{\mathrm{i}=1}^{\mathrm{N}} \varepsilon_{\mathrm{i}}^{2}$

Where $\varepsilon_{\mathrm{i}}=\ln \mathrm{Y}_{\mathrm{i}}-\ln \mathrm{X}_{\mathrm{i}} \beta$ is the residual of (3.3); $\mathrm{N}$ is the number of observations; $\Phi($.$) is the standard normal$ distribution; $\sigma^{2}=\sigma_{\mathrm{v}}^{2}+\sigma_{\mathrm{u}}^{2}$, and $\gamma=\sigma_{\mathrm{u}}^{2} / \sigma^{2}$ are variance parameters.

The minimization of (3.4) with respect to $\beta, \sigma^{2}$ and $\gamma$ and solving the resulting partial derivatives simultaneously, produces the ML estimates of $\beta, \sigma^{2}$ and $\gamma$. The $\gamma$ parameter is used to test whether the technical inefficiency affects output or not. Likewise, the significance of $\sigma^{2}$ indicates whether the conventional average production function adequately represent the data or not.

Elasticity of production: It is the measure the effect of change in the factor input output. In Cobb-Douglas production function, the regression coefficients stand for the elasticity's of the individual resources (land, labor, seed, fertilizer, chemicals and oxen). The sum of these parameters indicates the nature of returns to scale, i.e., if the sum is equal to 1 , it indicates constant returns to scale, if it is greater than 1 , it shows increasing returns to scale and if sum is less than 1 it implies that decreasing returns to scale.

\section{RESULT AND DISCUSSION}

This section is divided into two main sections: descriptive statistics and econometric (stochastic frontier) results. The first section reports the descriptive results to describe Technical efficiency variables used in the study. The second part of this section presents the econometric results of the Cobb-Douglas stochastic production function.

\section{Descriptive Analysis Results}

\section{Household characteristics}

The survey result showed that the total numbers of married, widowed, divorced and sample households during the survey period were $78.23 \%, 3.23 \%, 6.45 \%$ and $12.1 \%$ respectively. About $19.35 \%$ of the sample respondents were female headed and $80.645 \%$ were male headed. The average family size of the sample households was found to be 5.47, with minimum of 1 and maximum of 11 . The average age of sample household heads was 36.17 years with maximum of 75 years and a minimum of 18 years.

Table 5. Sex and marital status of sample households

\begin{tabular}{lcc}
\hline & Number of farmers & Percent \\
\cline { 2 - 3 } Marital status & 15 & 12.10 \\
Single & 8 & 6.45 \\
Divorced & 97 & 78.23 \\
Married & 4 & 3.23 \\
Widowed & 4 & \\
\hline Sex & & 80.645 \\
$\quad$ Male & 100 & 19.355 \\
\hline
\end{tabular}

Source: Own survey (2017)

From the total of sample household heads, $17.35 \%$ were illiterate, while the remaining $82.65 \%$ had different levels of education, ranging from grade one to completion of secondary school. The maximum number of school years completed by the household heads was eleven years. About $27.42 \%, 45.96 \%$ and $7.26 \%$ of sample respondents attended 1 to 4,5 to 8 and 9 to eleven level of education, respectively. 


\section{Farming experience}

There is a wide range of farming experience in the study area, varying from 2 to 55 years. The average farming experience of sample households was 18.06 years. The average wheat production experience was 5.87 years with a minimum of 1 year and maximum of 9 years. The average time to reach their farm was about 40.92 walking minutes.

\section{Livestock ownership}

Livestock is an important component of the farming system practiced by the farmers, and it is an important asset for rural households in Horo districts of Horoguduru Wollega Zone in Oromia regional state and serves multiple purposes. Cattle provide draught power for crop cultivation, manure for household fuel, organic fertilizer, meat, milk and other products like hides and skin. Donkey is used for transportation. Farmers in the study area use oxen to undertake different agronomic practices, out of which plough and threshing were the major once. Table 6 Distribution of oxen ownership among sample households

\begin{tabular}{lcc}
\hline \multicolumn{2}{l}{ Oxen ownership category } & Sample households \\
\hline \multicolumn{1}{c}{ Number } & \multicolumn{2}{l}{ Percent } \\
\cline { 2 - 3 } None & 18 & 14.52 \\
1 ox & 23 & 18.55 \\
2 oxen & 57 & 45.97 \\
3 oxen & 7 & 5.65 \\
4 oxen & 11 & 8.87 \\
5 and more oxen & 8 & 6.46 \\
\hline
\end{tabular}

Source: Own survey (2017)

Conventionally, land preparation is done using a pair of oxen; as a result $33.7 \%$ of the sample households cannot independently plough their farm using own oxen. Hence, as an alternative, they will go for oxen exchange arrangements or rent-in from others. Oxen ownership among farmers in the study area was ranging from zero to seven. Generally, $45.97 \%$ of sample households in the study area have had a pair of oxen. Actually in the study area, small ruminants are used to meet immediate cash need of the households and also for meat production both for cash and home consumption especially during holidays. Poultry is kept for egg and meat production both for cash and home consumption. In most cases farmers kept oxen as a source of draught power, cows are important sources of milk and milk products for consumption and satisfy immediate cash through the sale of butter. To make the unit of measurement uniform conversion factor developed by Storck, et al (1991) as cited in Arega and Rashid (2005) was used to convert the herd size to in TLU.

Table 7. Distribution of Livestock holding among sample households

\begin{tabular}{lcc}
\hline TLU range & \multicolumn{2}{c}{ Total sample households } \\
\cline { 2 - 3 } & Frequency & Percent \\
\hline $0.00-2.00$ & 91 & 73.39 \\
$2.01-4.00$ & 18 & 14.52 \\
$4.01-6.00$ & 9 & 7.258 \\
$6.01-8.00$ & 2 & 1.613 \\
$\geq 8.01$ & 4 & 3.226 \\
\hline
\end{tabular}

Source: Own survey (2017)

Table 5 shows that $73.39 \%$ of the total sample households have had less than or equal to two TLU. Only $26.61 \%$ of the total sample households have had greater than or equal to two TLU of which $21.778 \%$ ranges between two and six TLU. This means, on average, only $4.84 \%$ of the households have had greater than six TLU. Oxen ownership of sample household ranges from 0 to 7 with a mean and standard deviation of 1.99 and 1.44 respectively, while the total number of TLU ranges from 0 to 10.55 with a mean and standard deviation of 1.67 and 2.19 , respectively.

\section{Crop type and production}

The farming system of the district is mixed crop-livestock where crop plays the major role in the households' income. The major crops grown in the area include wheat, maize, sorghum, and nug. The study area is characterized by cereal-based cropping system in which maize dominates. Barley is also an important crop next to wheat. Regarding the proportion of the area allocated for crops, most respondents had allocated more than half of 
their total land for the production of Wheat and maize in 2016/17 production season.

Table 8 . Major crops produced by sample households during 2016/17 production year

\begin{tabular}{lccccccccc}
\hline & \multicolumn{3}{c}{ Production area (ha) } & \multicolumn{5}{c}{ Production (Qt) } \\
Crop type & $\mathrm{N}$ & Min & Max & Mean & Std. & Min & Max & Mean & Std \\
\hline Wheat & 124 & 0.125 & 3.0 & 1.012 & 0.65 & 0.5 & 19 & 13.54 & 3.74 \\
Maize & 81 & 0.25 & 2.0 & 0.975 & 0.41 & 8 & 80 & 34.5 & 0.82 \\
Sorghum & 101 & 0.125 & 1.0 & 0.259 & 0.25 & 1 & 10.5 & 3.36 & 0.41 \\
\hline
\end{tabular}

Source: Own survey (2017)

\section{Resource use}

Obviously, farmers use different combination of inputs, such as land, fertilizer (organic and/or inorganic), seed (improved and/or local), Chemical (herbicide and pesticide), labor and draft powers in the production process. All sample respondents use non-selective herbicide chemical (round up) on their Wheat field because of frequent occurrence of weed infestation. Almost all the sample households use their own seed which were originally distributed by district bureau of agriculture and saved from previous harvest. Family labor, 'debo' and Hired labor were the main sources of labor input for major farming activities like plowing, weeding and harvesting in the production of Wheat.

\section{Off/non-farm activities}

Farmers in the study area were engaged in various off/non-farm activities other than the main farming activities during the survey year. This may be due to the meager returns they obtain from the agricultural activities. The off/non-farm activities in which the farmers were engaged include selling local drink, butchery, handcrafts, sand carpenter and retailer. The income they desperately need to obtain from such off/non-farm activities supplements the low income usually obtained from their farming main stay. About $45.2 \%$ of the sample farmers reported that they participated in different off/non-farm activities, while the remaining $54.8 \%$ responded that they did not participate in any off/non-farm activities. This shows that, almost more than half of the sample farmers in the study area highly dependent on agriculture.

\section{Institutional support \\ Extension contact}

In order to give effective extension service to the farmers, the region assigned three DAs in each kebele. This can help the farmers to know modern agricultural technologies. The concept of agricultural growth suggests two channels of impacts of extension in agriculture. The first channel is to assist the destination of new technologies to farmers as a way of increasing agricultural productivity thus speeding up adoption or the use of new technologies and practices. The second channel is the role of extension in improving human capital and management skills of farmers to improve their level of technical efficiency (O'Neill et al., 2001). Different extension programs have been implemented to support farmers and it is well known that there is a change in the use of agricultural technologies such as fertilizer and improved seeds over the past 15 years. This would not assure improvement in efficiency. There were no improved seeds and the farmers use only local Wollega wheat with non-selective chemical fertilizer in the study area.

\section{Credit and saving services}

Oromia credit and saving Share Company is the only formal source of credit in the study area. It provides credit to individual farmers under group collateral system. Out of the total $69.35 \%$ sample households who had credit access, $30.64 \%$ of them get their credit from OCSSCO while the other $38.71 \%$ respondents get it from informal sources like relatives and neighbors. The households use the credit to purchase inputs, for medication and fulfillment of other basic needs.

Table 9. Distribution of credit source among sample households

Credit source $\quad$ Total Sample Households

\begin{tabular}{lll} 
& Frequency & Percent \\
\hline Oromia Credit and saving share company & & 30.64 \\
Relatives and neighbors & 38 & 38.71 \\
Total & 48 & 69.35 \\
\hline
\end{tabular}

Source: Own survey (2017) 


\section{Descriptive statistics of variables used in the stochastic frontier model}

The production function for this study was estimated using six input variables. On average farmers produced 13.54 quintals of wheat, which is the dependent variable in the production function. The land allocated for wheat production, by the sample households during the survey period, ranges from 0.125 to 3 ha with average of 0.95 ha. The average amount of seed that sample households' used was $26.8 \mathrm{Kg}$. Like other inputs human and animal labor inputs were also decisive, given the traditional farming system in the study area.

Table 10. Descriptive statistics of variables used to estimate the production function

\begin{tabular}{llccc}
\hline Variable description & Minimum & Maximum & Mean & Std. deviation \\
\hline Output (Qt) & 3 & 54 & 13.54 & 9.52 \\
Land (ha) & 0.125 & 3 & 0.95 & 0.82 \\
Seed (Kg) & 6 & 100 & 26.8 & 17.9 \\
DAP (Kg) & 16 & 200 & 44.5 & 24.20 \\
Labor (MDs) & 12.5 & 159.06 & 50.11 & 28.74 \\
Chemical (Lts) & 0.375 & 9 & 2.85 & 1.48 \\
Oxen (days) & 1.875 & 40.375 & 12.26 & 7.76 \\
& & & & \\
\hline
\end{tabular}

Source: Own survey (2017)

Sample households, on average, use 50.11 man equivalent labor and 12.26 oxen days for the production of wheat during 2016/17 production season. In the study area farmers use only DAP for wheat production. Hence, on average farmers used $44.5 \mathrm{Kg}$ of DAP. The other very important variable is chemicals. The average amount of chemicals that sample households used was 2.85 Liter during production period (Table 6 )

\section{Estimated observed and potential (frontier) level of output}

The difference between the actual level and the frontier level of output was computed by estimating the individual and the mean level of frontier output. Using the values of the actual output obtained and the predicted technical efficiency indices, the potential output was estimated for each sample farm households. The mean levels of the actual and frontier output during the production year were 13.54Qt and 26.7Qt/ha, with the standard error of 3.74 and 4.25, respectively. Moreover, paired sample t-test was used on the actual and potential output to compare the difference in the amount of yield between two scenarios. There was a significantdifference between potential output and actual output. The mean difference of the actual and the potential output was found to be statistically significant at $1 \%$ probability level.

Table 11. Comparison of estimated actual and potential output of sample households

Actual (observed) Output

\begin{tabular}{llllll} 
Efficiency category & $\mathrm{N}$ & Mean & Std. Deviation & Mean & Std. Deviation \\
\hline $0.3-0.6999$ & 37 & 6.5 & 4.27 & 3.514 & 3.13 \\
$0.7-0.7999$ & 43 & 7.15 & 4.26 & 4.66 & 3.07 \\
$0.8-0.8999$ & 23 & 7.166 & 3.86 & 5.92 & 3.5 \\
$0.9-0.9999$ & 21 & 8.48 & 4.58 & 8.1 & 4.46 \\
Overall & 124 & 26.7 & 4.25 & 13.54 & 3.74 \\
\hline Paired sample t-test & & & & $\mathrm{t}=13$ \\
\hline
\end{tabular}

Source; own survey 2017

\section{Econometric Result}

This section presents the econometric results of the study. The results of production and cost functions, efficiency scores and determinants of efficiency are discussed successively.

\section{Multicollinearity test}

Before running to the econometric analysis, Multicollinearity test for all variables was done using Variance Inflation Factor (VIF). Test for multicollinearity for all variables confirmed that there was no serious linear relation among explanatory variables.

Estimation of production and cost functions

Technical efficiency levels in wheat production in Horo districts were estimated using stochastic frontier 
production function (SFP). Input variables such as area under wheat cultivation (Land) (ha), oxen (days), labor (MD), quantity of seed $(\mathrm{Kg})$, DAP $(\mathrm{Kg})$ and amount ofchemical in literswere used in the model for estimating technical efficiency. These results together with the standard OLS estimates of the average production function are presented below.

Table 12. MLE results of the production frontier for the sample households

\begin{tabular}{lccc}
\hline Variable & Coefficient & Standard error & p-value \\
\cline { 1 - 2 } Constant & 0.133 & 0.44 & 0.54 \\
Land & $0.04^{* *}$ & 0.022 & 0.04 \\
Seed & $0.66^{* * *}$ & 0.042 & 0.00 \\
Dap & $0.22^{* * *}$ & 0.034 & 0.00 \\
Oxen & 0.002 & 0.018 & 0.67 \\
Labor & 0.024 & 0.22 & 0.34 \\
Chemical & $0.144^{* * *}$ & 0.04 & 0.001 \\
Diagnostic statistics & & & \\
Gamma $(\gamma)$ & $0.88^{* * *}$ & & \\
Sigma square & $0.35^{* * *}$ & 0.072 & \\
Lamda & $2.88^{* * *}$ & 0.11 & \\
log likelihood & 161.11 & & \\
\hline
\end{tabular}

Note: $* *$ and $* * *$ refers to $5 \%$ and $1 \%$ significance level, respectively.

Source: Own computation (2017)

From the total of six variables considered in the production function, three (Land, seed, Dap and Chemical) had positive sign and significant effect in explaining the variation in wheat output among farmers and are significant variables in shifting the frontier output to the right or moving along the frontier. This indicated that a unit increase of these variables; increase the level of wheat output. The coefficients of the production function are interpreted as elasticity. Hence, elasticity of output to land (0.04) suggests that $1 \%$ increase in size of land will result in $0.04 \%$ increase in wheat production, keeping other factors constant. Alternatively, this indicates wheat production was responsive to land, seed, DAP and chemical in the study area. The productions function estimated from stochastic frontier model results:

Ln Y $=0.13+0.04 \ln ($ land $)+0.66 \ln ($ seed $)$

$+\mathbf{0 . 2 2} \ln (\mathbf{D A P})+0.26 \ln$ (labor)

$+0.21 \ln ($ Oxen $)+0.144 \ln$ (Chemical) $+\varepsilon_{i}$

The diagnostic statistics of inefficiency component reveals that sigma squared $\left(\sigma^{2}\right)$ was 0.35 and statistically significant at 1 percent this indicates goodness of fit, and the correctness of the distributional form assumed for the composite error term. Using the formula in equation (3.3) the gamma $(\gamma)$ was 0.88 which was high enough and significant at $1 \%$ level. It gives an indication that the unexplained variations in output are the major sources of random errors. It also shows that about 88 percent of the variations in output of wheat farmers are caused by technical inefficiency. It also confirms the presence of the one sided error component in the model; this rendering the use of ordinary least squares (OLS) estimation techniques inadequate in representing the data.

The returns to scale analysis can serve as a measure of total factor productivity (Ajibefun, 2002). The scale coefficient was calculated to be 1.09, indicating increasing returns to scale (Table 14). This implies that there is potential for wheat producers to continue to expand their production because they are in the stage I of the production surface, where resource use and production is believed to be inefficient. In other words, a one percent increase in all inputs proportionally will increase the total production by $1.09 \%$. This result is consistent with Hika (2016),Ermias et al.(2015) and DOO (2013).

Table 13. Elasticity and returns to scale of the parameters in the production fuction

\begin{tabular}{lc}
\hline Variables & Elasticity \\
\hline Land & 0.044 \\
Seed & 0.661 \\
DAP & 0.221 \\
Labor & 0.024 \\
Oxen & 0.002 \\
Chemical & 0.144 \\
Return to scale & 1.09 \\
\hline
\end{tabular}

Source: Own computation (2017) 


\section{Estimation of efficiency scores}

The results of the efficiency scores indicate that there were wide ranges of differences in TE among wheat producer farmers. The mean TE of sample households during the survey period was $63.9 \%$. The TE among the households ranges from $35.4 \%$ to $99.6 \%$, with standard deviation of 0.187 . This result is consistent with study of Jema (2008), Wondimu (2010), Ermias et al.(2015), mustefa (2014) and Hika(2016)

Table 14. Descriptive statistics of efficiency measures

\begin{tabular}{llllll}
\hline Variable & Obs & Mean & Std. Dev. & Min & Max \\
\hline TE & 124 & 0.6397 & 0.187 & 0.354 & 0.996
\end{tabular}

\section{Source: Own computation (2017)}

The results in Table 16 indicate that the average level of TE was $63.9 \%$ which reveals that farmers on average could decrease inputs (land, DAP, Oxen, labor, seed and chemical) by $36.1 \%$ to get the output they are currently getting, if they use inputs efficiently.

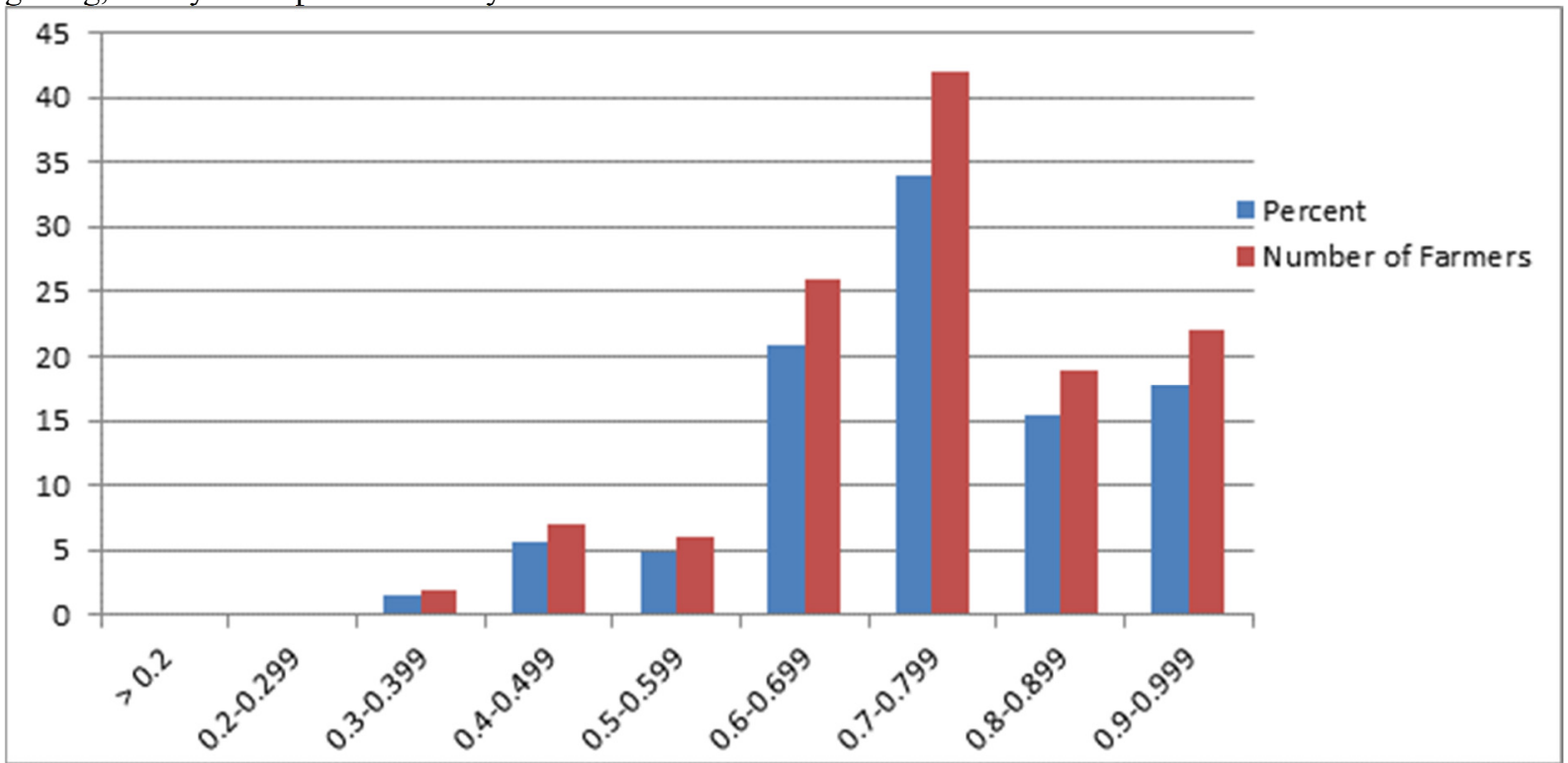

Figure 2. Distribution of technical efficiency scores

Source: Own computation (2017)

The distribution of the TE scores showed that the majority (more than 66.93\%) of the sample households had TE score of greater than $70 \%$ (Figure 6). But there were also some households whose TE levels were limited to the range 20 to $40 \%$. Households in this group have a room to enhance their wheat production at least by $70 \%$, on average. Out of the total sample households, only $17.74 \%$ had TE greater than $90 \%$. This implies that about $82.26 \%$ of the households can increase their production at least by $10 \%$.

\section{Determinants of efficiencies in sample farmers}

After determining the presence of efficiency differential among farmers and measuring the levels of their efficiency, finding out factors causing efficiency differentials among farmers was the next most important objective of this study. To see this, the technical efficiency estimates derived from the model were regressed on socio-economic and institutional variables that explain the variations in efficiency across farm households using stochastic frontier model. The estimates of the model showed that among 11 variables used in the analysis, family size, total cultivated land, extension contact, and experience in wheat production were found to be statistically significant in affecting the level of TE of farmers. 
Table 15. Stochastic model estimates for different efficiency measures

\begin{tabular}{lccl}
\hline Variable & Coefficient & Standard error & $\mathrm{P}>[\mathrm{Z}]$ \\
\hline Constant & 0.28 & 0.177 & 0.000 \\
Age & 0.003 & 0.002 & 0.124 \\
Education level & 0.002 & 0.012 & 0.577 \\
Wheat exp & $0.027^{* * *}$ & 0.009 & 0.007 \\
Family size & $0.03^{* * *}$ & 0.009 & 0.002 \\
Total cult & $-.011^{* * *}$ & 0.0036 & 0.001 \\
Proximity & 0.006 & 0.008 & 0.470 \\
Nonfarm income & -.0031 & 0.0046 & 0.505 \\
Soil fertility & 0.0067 & 0.0047 & 0.153 \\
Extension cont & $0.0422 * * *$ & 0.0065 & 0.000 \\
TLU & 0.0012 & 0.0013 & 0.357 \\
Credit access & 0.0065 & 0.005 & 0.196 \\
\hline
\end{tabular}

Note: $* *$ and $* * *$ refers to $5 \%$ and $1 \%$ significance level, respectively.

Source: Own computation (2017)

The discussion about each significant variable are presented as follows:

Family size: The coefficient of family size for technical efficiency is positive and statistically significant at 1 percent significance level. The result is similar to the previous expectation that Farmers those having large family size are more efficient than farmers having small family size, because; family labor is the main input in crop production as the farmer has large family size he would manage crop plots on time and May able to use appropriate input combinations. This is in line with the findings of Mohammed et al. (2009), Essa (2011), Mustefa (2014) and Hika (2016).

Wheat production experience: The coefficient of experience is positive as expected for TE and significant at 1 percent. This indicated that increased farming experience may lead to better assessment of importance and complexities of good farming decision, including efficient use of inputs.

Total cultivated land: Total cultivated or farm land was found to have significant and negative impact on TE. This might be due to the fact that the increased land size reduces technical efficiency by creating shortage of family labor, management and other resources that should have been available at the same time for wheat production but on the different product like noug, maize and sorgum in the study area. This result is in line with the results of Coelliet al. (2005), Jema (2008), Hika (2016) and OkezieChukwukere (2012).

Extension contact: extension contact was found to have a positive and significant relationship with technical efficiency of farmers. This might be due to the fact that the involvement of extension workers in supporting and advising through providing good inputs which is appropriate for production of wheat that increase productivity and efficiency score in the long run. The result is consistent with Jema (2008) and Ermiaset al.(2015).

\section{Summary and Conclusion}

Agricultural sector in Ethiopia is characterized by its poor performance, whereas the population of the country, which to a large extent depends on agriculture, is growing at a faster rate. This necessitates seeking for a means to increase agricultural productivity of smallholder farmers, the dominant producers, which could either be met through improving the state of technology or enhancing the efficiency of producers. Alternatively, productivity growth may attribute to either technological progress or efficiency improvement. Improving efficiency of the farmer plays a great role in increasing productivity, given the current state of technology. This study analyzed the technical efficiency and factors that explain the variation in efficiency among wheat producer farmers in Horo district of Horo-guduru wollega zone, Oromia, Ethiopia.

In this study both primary and secondary data were used. Primary data were collected through household survey from a sample of 124 households using a semi-structured questionnaire. Secondary data were collected from relevant sources to supplement the primary data. Data analysis was carried out using descriptive statistics and econometric techniques.

Result of the Cobb Douglas production function indicated that Land, seed, DAP and chemical were limiting constraints, with positive sign as expected. The positive coefficients of these variables indicate that, increased use of these inputs will increase the production level to greater extent. The average TE, value was $63.9 \%$. This implies that farmers can increase their wheat production on average by $36.1 \%$ if they were technically efficient..

In the other part of the analysis, relationships between TE and various variables that were expected to have effect on farm efficiency were examined. This was relied on SPF regression techniques, where TE was expressed as functions of 11 explanatory variables. Among them, family size, experience in wheat production and extension contact positively and significantly affected TE. But total cultivated land had negatively significant impact on TE. These factors had important policy implications to alleviate the existing level of technical inefficiency of farmers in production of wheat. 
An important conclusion stemming from the analysis of the efficiency of wheat production is that, there exists a considerable room to enhance the level of technical efficiency of Wheat producer farmers. The implication is that, there will be considerable gain in production level and dissemination of agricultural technologies is coupled with improving the existing level of efficiency. Moreover, the study contributes to improve farm revenue, welfare and generally helps agricultural as well as economic development.

\section{Recommendations}

The policy implications of this analysis are that efficiency estimates indicate both the distribution of the farmers' efficiency and its socio-economic determinants. Thus, the results of the study give information to policy makers on how to improve farm level efficiency of wheat production and identify the determinants for specific efficiency types. The study results revealed that there is a considerable variability in all efficiencies and efficiency score of sample household in the production of wheat in the study area. This indicated that in the long run improving the existing level of technical efficiency of farmers alone may not lead to significant increment in the level of wheat. So in the long run it needs attention to introduce other best alternative farming practices and improved technologies in order to change the lives of farmers. The policy makers should give due emphasis to increase the level of efficiencies. This is because the use of improved technologies is expensive since it requires large capital. Thus, the following policy recommendations are forwarded based on the result of the study.

Family size was very important factor that contributed positively to the improvement of technical efficiency of wheat. So, development agent and Ethiopian government should give more attention to provide good training on how to allocate family labor on production that increase wheat productivity in the study area.

Total cultivated land affect technical efficiency of farmers negatively. Therefore, development programs agents of the study area should give due emphasis to improve and maintain wheat productivity through awareness creation on time and budget allocation for inputs and introduction of technologies so that the efficiency of the farmers increases.

The result of the finding also indicated that extension contact was found to affect technical efficiency of wheat producer positively. Despite the justification given by this study, it needs further support to encourage development agent in order to increase productivity wheat in the study area.

Experience in wheat production was found to affect technical efficiency positively. This indicates that increased farming experience may lead to better assessment of importance and complexities of good farming decision, including efficient use of inputs. Thus, the government should facilitate the infrastructure (especially road) to improve the market network of wheat producer which encourages the farmers to produce effectively and supply their products to the market with low transportation cost that increase farmers experience in the long run.

\section{REFERENCES}

AbebayehuGirma, 2011.Technical Efficiency of Haricot Bean Seed Production in Boricha District of Sidama Zone, Southern Ethiopia. M.Sc. Thesis Presented to School of Graduate Studies of Haramaya University.

Aigner, D.J. and S.F. Chu, 1968.On Estimating the Industry Production Function.American Economic Review, 58(4): 826-839.

Aigner, D.J., K.C.A. Lovell and P.S. Schmidt, 1977.Formulation and Estimation of Stochastic Models.Journal of Econometrics, 6: 21-37.

Ajibefun, I.A., 2002. An Evaluation of Parametric and Non-parametric Methods of Technical Efficiency Measurement: Application to Small Scale Food Crop Production in Nigeria. Journal of Agricultural and Social of Sciences, 4: 95-100.

Amos T.T. 2007.An Analysis of Productivity and Technical Efficiency of Smallholder Cocoa Farmers in Nigeria.Journal of Social Science, 15(2): 127-133.

AregaAlene and M. H. Rashid, 2005. The Efficiency of Traditional and Hybrid Maize Production in Eastern Ethiopia: An Extended Efficiency Decomposition Approach. Journal of African Economics, 15: 91-116.

AynalemGezahegn, 2006. Technical Efficiency in Maize Production: A Case of Smallholder Farmers in Mecha District, Ethiopia. M.Sc. Thesis Presented to the School of Graduate Studies of Alemaya University.

AbayAsfaw and AssefaAdmassie, 1996. The Impact of Education on Allocative and Technical Efficiency of Farmers: The Case of Ethiopian Small Holders. Ethiopian Journal of Agricultural Economics 5(1): 1-26.

Ajibefun I. A., G. E. Battese and A.G. Daramola, 1996. Investigation of Factors Influencing Technical Efficiecnies of Smallholder Croppers in Nigeria, CEPA Working Papers, No. 10/96, Department of Econometrics, University of New Englad, Armidale.

Ajibefun I. A., G. E. Battese and R. Koda, 1996. Technical Efficiency and Technological Change in the Japanese Rice Industry: A Stochastic Frontier Analysis, CEPA Working Papers, No. 9/96, Department of Econometrics, University of New Englad, Armidale.

Ajibefun I.A. 2002. Analysis of Policy Issues in the Technical Efficiency of Small Scale Farmers Using the Stochastic Frontier Production: With Application to Nigerian Farmers. Paper Prepared for Presentation at the 
International Farm Management Association Congress, Wageningen, The Netherlands.

AmareGebreEgziabher, 1998. Efficiency of Small-Scale Farming in Toyo District, Arsi: A Quadratic Risk Programming Approach. Ethiopian Journal of Agricultural Economics, 2(1): 1 - 26.

Apezteguía B.I. and M.P. Garáte, 1997.Technical Efficiency in the Spanish Agro Food Industry. J. Agricultural Economics, 17, 179 - 189.

Arega D. Alene and Rashid M. Hassan and Mulat D., 2000. The Technical, Allocative and Economic Efficiency of Maize Production Under Improved Technology in the Bako Area of Western Oromia: A Stochastic Efficiency Decomposition Approach.

Arega D. Alene and Rashid M. Hassan, 2002. Measuring the Impact of Ethiopia's New Extension Program on the Productive Efficiency of Farmers, Contributed Paper Selected for Presentation of the $25^{\text {th }}$ International Conference of Agricultural Economics, August 16 - 22, 2002, South Africa.

BefkaduDegife and BerhanuNefa, 2000.Annual Report on the Ethiopian Economy, Addis Ababa.

Banker R., A. Charnes and W. Cooper, 1984. Some Models for Estimating Technical and Scale inefficiencies in Data Envelopment Analysis. Management Science, 30:9, 1078 - 1092.

Battese G.E., 1998.A Methodological Note on a Stochastic Production Frontier Model for the Analysis of the Effects of Quality of Irrigation Water on Crop Yields. The Pakistan Development Review, 37:3, 293 - 298.

Battese G.E. and S. Hassan, 1998.Technical Efficiency of Cotton Farmers in Vehari District of Punjab Pakistan.CEPA Working Papers, Department of Econometrics, University of New England, Armidale. No $8 / 98$.

Battese G.E. and T.J. Coelli, 1995.A Model for Technical Inefficiency Effects in a Stochastic Frontier Production Function for Panel Data. Empirical Economics, 20, 325 - 332.

BezabihEmana, 2000. The Role of New Varieties and Chemical Fertilizer under Risk: The Case of Smallholders in Eastern Oromia, Ethiopia. Ph.D. Dissertation, Department of Horticulture, University of Hannover, Shaker Verlag, Germany.

Bravo-Ureta B.E. and A. Pinheiro, 1997. Technical, Economic and Allocative Efficiency in Peasant Farming: Evidence from Dominica Republic. The Developing Economics, xxxv-1, 48-67.

Coelli T.J., 1995a. Estimators and Hypothesis Tests for Stochastic Frontier Function: A Monte Carlo Analysis. Journal of Productivity Analysis, 6, 247 - 268.

Coelli T.J., 1995b. Measurement and Source of Technical Efficiency in an Australian Electric Generation, Paper Presented at the New England, Armidale, November 23-24.

CSA (Central Statistical Authority), 2016.Statistical Report on Area and Crop Production. Addis Ababa, Ethiopia.

DawitAlemu and G.W. Meijerink (2010); Wheat Traders and the ECX: An Overview with Focus on Transaction Costs and Risks, VC4PPD Report \#8, Addis Ababa.

DawitKelemework, J.S. David and E.G.Fonsah, 2012.Innovation Systems and Technical Efficiency in Developing-Country Agriculture.Selected Paper Prepared for Presentation at the Southern Agricultural Economics Association Annual Meeting, Birmingham, AL.

Dolisca, F. and M.J. Curtis, 2008. Technical Efficiency of Traditional and Non-traditional Crop Production: A Case Study From Haiti. World Journal of Agricultural Sciences, 4(4): 416-426.

Farrell, M.J., 1957. The Measurement of Productive Efficiency.Journal of Royal Statistical Society. Series A, 120: 253-290

FekaduGelaw, 2004. Analysis of Technical Efficiency of Wheat Production: A Study in Machkel District. M.Sc. Thesis Presented to School of Graduate Studies of Haramaya University.

GetuHailu, 1997. Analysis of Performance Variation: The Case of Smallholder Farms in Eastern Hararghe Region. Unpublished M.Sc Thesis, Alemaya University.

Gstach D. 1998.Technical Efficiency in Noisy Multi-output Settings. Working Paper, No. 59, Vienna University of Economics, Vienna.

Herrero I. and S. Pabcoe, 2001. Estimation of Technical Efficiency: A Review of some of the Stochastic Frontier and DEA Software. The Virtual Economics, Vol. 15, 1-11.

Heshmati A. and S.C. Kumbhakar, 1997. Estimation of Technical Efficiency in Swedish Crop Farms: A Pseudo Panel Data Approach. J. Agricultural Economics, 48(1), 22 - 37.

HikaWana. And Jema Haji, 2016. Economic efficiency of sesame production in Babogambel District of west wollega zone, oromia, Ethiopia. Unpublished M.Sc Thesis, Haramaya.

Mohamed M. Ahmed, BerhanuGebremedihin, Samuel Benin and SineonEhui, 1994. Measurement of Land Tenure Contracts in Ethiopia. Environment and Development Economics, 507 - 526.

Mohammad Hassena, H Farah. W. Mwangi and Belay K.1999. Factors Influencing Technical Efficiency of Crop Production in Assassa District of Southern Ethiopia.

Mohammad Hassena, H Farah. W. Mwangi and Belay K.2000. Factors Influencing Technical Efficiency of Barely Production in Assassa District of Southern Ethiopia, Ethiopian Journal of Agricultural Economics, 4 (1/2): 1 $-22$. 
Mohammad J and E. Premachandra, 2003. Sensitivity of Technical Efficiency Estimates to Estimation Approaches: An Investigation Using New Zealand Dairy Industry Data. University of Otago, Economics Discussion Papers No. 0306.

MulatDemeke and BekeleHundie. 2001. The Determinants of Yield of Major Cereals: The Contribution of New Technologies in Selected Villages of Ethiopia, Proceeding of National Workshop on Technological Progress in Ethiopian Agriculture Nov. 29 - 30, Addis Ababa, Ethiopia.

Sharma K.R., P.S. Leung and H.M. Zalaski, 1999. Technical, Allocative and Economic Efficiencies in Swine Production in Hawaii: A Comparison of Parametric and Nonparametric Approaches. J. Agricultural Economics, 20, 23 - 35.

Strock H., BezabihEmana, BerhanuAdenew, A. Borowiecki and Shimelis W/Hawariate (1991). Farming Systems and Farm Management Practices of Smallholders in the Hararghe Highlands.

Wilson P., D. Hadley, S. Ramsden and I. Kaltsas, 1998. Measuring and Explaining Technical Efficiency in UK Potato Production. Journal of Agricultural Economics 49(3),294-305.

Yamane, T.I., 1967. Statistics: An Introductory Analysis $2^{\text {nd }}$ Edition. New York, Harper and Row.

\section{APPENDICES}

Appendix 1.Technical efficiency score of the sample household

\begin{tabular}{|c|c|c|c|c|c|}
\hline 1 & 0.36694 & 43 & 0.5253 & 85 & 0.592137254 \\
\hline 2 & 0.56206 & 44 & 0.9629 & 86 & 0.367886709 \\
\hline 3 & 0.50588 & 45 & 0.8215 & 87 & 0.415813376 \\
\hline 4 & 0.51290 & 46 & 0.590153804 & 88 & 0.520921771 \\
\hline 5 & 0.73254 & 47 & 0.458498535 & 89 & 0.541973799 \\
\hline 6 & 0.55923 & 48 & 0.414551029 & 90 & 0.507871925 \\
\hline 7 & 0.66551 & 49 & 0.964364498 & 91 & 0.354367933 \\
\hline 8 & 0.38019 & 50 & 0.952544386 & 92 & 0.921348451 \\
\hline 9 & 0.73099 & 51 & 0.98841641 & 93 & 0.526343197 \\
\hline 10 & 0.60765 & 52 & 0.629931704 & 94 & 0.792471016 \\
\hline 11 & 0.56392 & 53 & 0.910244801 & 95 & 0.660647916 \\
\hline 12 & 0.40819 & 54 & 0.488980882 & 96 & 0.50405963 \\
\hline 13 & 0.39759 & 55 & 0.626109078 & 97 & 0.739108211 \\
\hline 14 & 0.37989 & 56 & 0.59720533 & 98 & 0.362293443 \\
\hline 15 & 0.65147 & 57 & 0.689312518 & 99 & 0.5199508 \\
\hline 16 & 0.41216 & 58 & 0.446128891 & 100 & 0.759435081 \\
\hline 17 & 0.73048 & 59 & 0.682532543 & 101 & 0.863808477 \\
\hline 18 & 0.37003 & 60 & 0.687095899 & 102 & 0.541612194 \\
\hline 19 & 0.89069 & 61 & 0.76205719 & 103 & 0.408777736 \\
\hline 20 & 0.60423 & 62 & 0.498143889 & 104 & 0.487832905 \\
\hline 21 & 0.43546 & 63 & 0.759539085 & 105 & 0.783260439 \\
\hline 22 & 0.92226 & 64 & 0.400325476 & 106 & 0.42883906 \\
\hline 23 & 0.53973 & 65 & 0.770784845 & 107 & 0.959343137 \\
\hline 24 & 0.45187 & 66 & 0.529715925 & 108 & 0.953750161 \\
\hline 25 & 0.48794 & 67 & 0.960730635 & 109 & 0.764656057 \\
\hline 26 & 0.95795 & 68 & 0.996420391 & 110 & 0.611015578 \\
\hline 27 & 0.97269 & 69 & 0.756867643 & 111 & 0.604066511 \\
\hline 28 & 0.88317 & 70 & 0.739177388 & 112 & 0.66339441 \\
\hline 29 & 0.81528 & 71 & 0.51184 & 113 & 0.752247802 \\
\hline 30 & 0.81074 & 72 & 0.86527 & 114 & 0.371163683 \\
\hline 31 & 0.41461 & 73 & 0.8107 & 115 & 0.440214694 \\
\hline 32 & 0.60246 & 74 & 0.3660 & 116 & 0.836107841 \\
\hline 33 & 0.51770 & 75 & 0.7855 & 117 & 0.426855725 \\
\hline 34 & 0.92828 & 76 & 0.51311 & 118 & 0.612670129 \\
\hline 35 & 0.55038 & 77 & 0.69366 & 119 & 0.517769652 \\
\hline 36 & 0.534407 & 78 & 0.93453 & 120 & 0.672004382 \\
\hline 37 & 0.892190 & 79 & 0.74969 & 121 & 0.767832625 \\
\hline 38 & 0.573048 & 80 & 0.73612 & 122 & 0.505275285 \\
\hline 39 & 0.876854 & 81 & 0.47757 & 123 & 0.708749138 \\
\hline 40 & 0.453460 & 82 & 0.455236 & 124 & 0.951031026 \\
\hline
\end{tabular}




\begin{tabular}{|l|l|l|l|l|l|}
\hline 41 & 0.83407 & 83 & 0.759280 & & \\
\hline 42 & 0.368866 & 84 & 0.489901 & & \\
\hline
\end{tabular}

Appendix 2. Conversion factors for man equivalent and adult equivalent

\begin{tabular}{|l|l|l|l|l|}
\hline \multirow{2}{*}{ Age group (years) } & Man Equivalent & Adult Equivalent \\
\cline { 2 - 5 } & Male & Female & Male & Female \\
\hline$<10$ & 0 & 0 & 0.6 & 0.6 \\
\hline $10-13$ & 0.2 & 0.2 & 0.9 & 0.8 \\
\hline $14-16$ & 0.5 & 0.4 & 1.0 & 0.75 \\
\hline $17-50$ & 1.00 & 0.8 & 1.0 & 0.75 \\
\hline$>50$ & 0.7 & 0.5 & 1.0 & 0.75 \\
\hline
\end{tabular}

Source: Storcket al. (1991)

Appendix3.Conversion factors used to estimate tropical livestock unit equivalents

\begin{tabular}{|l|l|}
\hline Animal category & TLU \\
\hline Calf & 0.25 \\
\hline Weaned Calf & 0.34 \\
\hline Donkey (Young) & 0.35 \\
\hline Donkey (adult) & 0.70 \\
\hline Camel & 1.25 \\
\hline Heifer & 0.75 \\
\hline Sheep and Goat (adult) & 0.13 \\
\hline Caw and Ox & 1.00 \\
\hline Sheep and Goat young & 0.06 \\
\hline Mule & 1.10 \\
\hline Chicken & 0.013 \\
\hline
\end{tabular}

Source: Storcket al. (1991) 